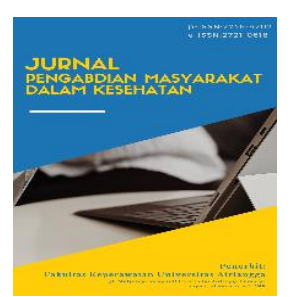

\section{JURNAL PENGABDIAN \\ MASYARAKAT DALAM KESEHATAN}

Vol. 2 No. 2, Oktober 2020

Laman Jurnal: https://e-journal.unair.ac.id/IPMK
This is an Open Access article distribute under the terms of the Creative Commons Attribution 4.0 International License

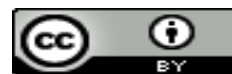

\title{
EDUKASI MANAJEMEN DIRI DALAM MENINGKATKAN EFIKASI DIRI, MENGENDALIKAN KADAR GULA DARAH DAN MENINGKATKAN KUALITAS HIDUP PADA PASIEN DIABETES MELLITUS
}

\author{
Agustina Boru Gultom dan Indrawati Indrawati \\ Poltekkes Kemenkes Medan, Indonesia
}

RIWAYAT ARTIKEL

Diterima: 27 Juli 2020

Disetujui: 15 Oktober 2020

\section{KONTAK PENULIS}

Agustina Boru Gultom agustinagultom203@gmail.co $\underline{\mathrm{m}}$

Poltekkes Kemenkes Medan, Indonesia

Kutip sebagai:

\begin{abstract}
ABSTRAK
Pendahuluan: Kecamatan Pancur Batu merupakan salah satu kecamatan di Kabupaten Deli Serdang yang memiliki kasus diabetes mellitus yang cukup banyak dan merupakan 10 penyakit terbanyak diwilayah kerjanya dimana 2 desa yang cukup tinggi kasus tersebut adalah desa tuntungan 1 dan desa tuntungan 2 . Kasus diabetes mellitus erat kaitannya dengan kemampuan pasien dalam memanajemen dirinya dalam menghadapi penyakit yang berdampak pada efikasi diri, pengelolaan gula darah dan kualitas hidup. Pengabdian masyarakat ini bertujuan meningkatkan kemampuan masyarakat dalam peningkatan efikasi diri, pengendalian kadar gula darah dan peningkatan kualitas hidup.
\end{abstract}

Metode: Pengabdian masyarakat dilakuan pada 30 penderita diabetes mellitus dari desa Tuntungan I dan Tuntungan II. Kegiatan meliputi edukasi mengenai manajemen diri, demonstrasi senam kaki, pengukuran efikasi diri, pemeriksaan gula darah dan pengukuran kualitas hidup. Instrumen evaluasi efikasi diri diadopsi dari The Diabetes Management Self-Efficacy Scale (DMSES), kualitas hidup menggunakan kuesioner Short Form Health Survey (SF-36) dan efikasi diri dengan penghitungan skor instrumen, kadar gula darah dengan mengukur kadar gula darah, dan kualitas hidup dengan penghitungan skor instrumen kualitas hidup. Kegiatan dilaksanakan pada bulan Juli - Agustus 2019.

Hasil: Edukasi manajemen diri diabetes mellitus meningkatkan skor efikasi diri sebesar 6,23 , dan menurunkan skor kadar gula darah sebesar 3,53 sebelum dan sesudah edukasi serta meningkatkan skor kualitas hidup sebesar 10,17.

Kesimpulan: Edukasi manajemen diri diabetes mellitus dapat meningkatkan skor efikasi diri, dapat mengendalikan kadar gula darah dan dapat meningkatkan skor kualitas hidup. Kata Kunci:

edukasi manajemen diri diabetes mellitus; efikasi diri; kadar gula darah; kualitas hidup

Gultom, A, B., \& Indrawati, I. (2020). Edukasi Manajemen Diri dalam Meningkatkan Efikasi Diri, Mengendalikan Kadar Gula Darah dan Meningkatkan Kualitas Hidup pada Pasien Diabetes Mellitus. J. Pengabdian Masyarakat dalam Kesehatan., 2(2), 32-35. Doi: 10.20473/jpmk.v2i2.21002

\section{PENDAHULUAN}

Salah satu masalah kesehatan yang sering terjadi di seluruh belahan dunia adalah diabetes mellitus. Diabetes mellitus merupakan suatu gangguan kesehatan yang kompleks dan menahun yang memerlukan perawatan medis yang berkelanjutan dengan strategi pengurangan risiko dari berbagai faktor dalam rangka pengendalian gula darah. (Association, 2018)

Diperkirakan 422 juta jiwa orang dewasa yang mengalami diabetes mellitus di dunia pada tahun
2014, dan hal ini terjadi peningkatan bila dibandingkan pada tahun 1980 sebesar 108 juta jiwa. Terjadi peningkatan orang dewasa sejak tahun 1980 meningkat sebesar 4,7\% menjadi peningkatan pada tahun 2014 sebesar 8,5\%. (World Health Organization, 2016)

Banyak komplikasi yang terjadi akibat masalah diabetes mellitus. Komplikasi masalah diabetes mellitus diantaranya adalah masalah komplikasi metabolik, komplikasi penyakit mikrovaskuler, komplikasi penyakit makrovaskuler (Forbes \& Cooper, 2013) 
Prevalensi diabetes mellitus di Indonesia mengalami peningkatan berarti. Berdasarkan pemeriksaan darah pada penduduk umur $\geq 15$ tahun terjadi peningkatan prevalensi diabetes melitus dari tahun 2013 sampai dari 2018. Pada tahun 2013 prevalensi diabetes melitus sebesar $6,9 \%$ dan pada tahun 2018 mengalami peningkatan sebesar 8,5\% (Kemenkes RI, 2018)

Penyakit diabetes mellitus akan mengalami perubahan dari efikasi diri dan kecenderungan perubahan efikasi diri ke arah yang rendah. Efikasi yang rendah disebabkan berbagai faktor seperti umur, pendidikan, status sosial ekonomi, kurangnya informasi yang adekuat mengenai manajemen perawatan diri. Peningkatan efikasi diri sangat dibutuhkan pada pasien yang mengalami diabetes mellitus. Efikasi diri pada pasien diabetes berkaitan erat dengan kemampuannya dalam memanajemen dirinya dalam menghadapi penyakit yang dialami yang akhirnya berdampak pada pengendalian gula darah dan tentunya akan mengurangi komplikasi dan pada akhirnya akan meningkatkan kualitas hidup pasien diabetes ke arah yang lebih baik (Amelia et al., 2018)

Kemampuan pasien diabetes mellitus dalam melakukan manajemen diri sangat ditentukan oleh edukasi manajemen diri yang dilakukan. Edukasi manajemen diri diabetes dapat dilakukan di komunitas baik dirumah, klinik, sekolah atau di tempat kerja. (Gakhar et al, 2008). Hasil studi menunjukkan tindakan dengan menerapkan model pengembangan efikasi diri melalui pendekatan model keyakinan diri atau health belief melalui edukasi manajemen diri diabetes menunjukkan pengaruh yang signifikan dalam peningkatan kualitas hidup pasien diabetes mellitus. (Gultom \& Siregar, 2017)

Puskesmas Pancur Batu Kabupaten Deli Serdang mempunyai kejadian diabetes mellitus yang tinggi dan merupakan 10 penyakit terbanyak di wilayah kerjanya, dimana ada 2 desa yang tinggi kasus diabetes mellitus yaitu desa tutntungan 1 dan desa tuntungan 2. Berdasarkan dari kajian-kajian yang dilakukan, dibutuhkan untuk melakukan suatu upaya edukasi manajemen perawatan diri diabetes mellitus. Penyerapan informasi yang benar dan pengimplementasikan secara kontiniu hasil edukasi tersebut dharapkan dapat meningkatkan efikasi diri, mengendalikan kadar gula darah dan meningkatkan kualitas hidup.

Permasalah utama dari uraian diatas adalah belum adanya upaya edukasi manajemen perawatan diri diabetes mellitus yang secara khusus diberikan di wilayah kerja Puskesmas Pancur Batu dibuktikan dengan minimnya informasi mengenai informasi edukasi tersebut. Tujuan dilakukan kegiatan pengabdian kepada masyarakat adalah agar masyarakat yang mengalami diabetes mellitus mengalami peningkatan efikasi diri, pengendalian kadar gula darah dan peningkatan kualitas hidup.

\section{METODE}

Kegiatan pengabdian masyarakat di siapkan dalam 3 tahap yaitu tahap persiapan, tahap intervensi dan tahap evaluasi.

\section{Tahap Persiapan}

Di tahap ini, tim pengabdi melakukan survey awal terkait kasus DM dan melakukan pendekatan kepada pihak Puskesmas Pancur Batu dengan tujuan untuk memperoleh data, dan merencanakan kegiatan. Kemudian tim pengabdi menyusun hal-hal yang dibutuhkan antara lain sarana dan bahan yang digunakan dalam kegiatan, dan juga mengurus perizinan.

\section{Tahap Intervensi}

Tahap ini diawali dengan pemberian pre test pengukuran efikasi diri dan kualitas hidup dengan kuesioner dan pemeriksaan gula darah dengan alat pengukur gula darah.

Kegiatan pengabdian kepada masyarakat ini berupa edukasi manajemen diri diabetes mellitus oleh tim pengabdi dalam 1 kali pertemuan dengan waktu 2,5 jam dikemas dalam metode ceramah dan tanya jawab mengenai manajemen diri diabetes mellitus dengan tema meliputi gambaran diabetes mellitus, diet diabetes mellitus, aktifitas fisik, senam kaki dan perawatan kaki diabetes mellitus, perjalanan dan hari-hari sakit penyandang diabetes mellitus, manajemen stress, demonstrasi dan redemonstrasi mengenai senam kaki. Kegiatan ini selanjutnya dilakukan peserta secara mandiri ditempat masingmasing dengan bantuan modul edukasi manajemen diri diabetes mellitus. Sasaran dalam kegiatan ini adalah pasien diabetes mellitus sebanyak 30 orang, dimana 15 peserta berasal dari desa Tuntungan I dan 15 peserta lagi berasal dari desa Tuntungan II dengan waktu yang berbeda. Media yang digunakan dalam kegiatan ini berupa modul edukasi manajemen diri diabetes mellitus, 2 set alat pemeriksa gula darah, bahan untuk senam kaki, kuesioner untuk pengukuran karakteristik, efikasi diri dan kualitas hidup. 


\section{Tahap Evaluasi}

Kegiatan ini dilakukan setelah tahap intervensi. Pertemuan berikutnya adalah melakukan evaluasi atau post test dengan kuesioner dan alat yang sama di masing-masing lokasi baik di desa Tuntungan I maupun di desa Tuntungan II setelah lebih kurang 2 minggu intervensi dalam waktu yang berbeda. Penilaian yang dilakukan adalah mengukur efikasi diri dan kualitas hidup dengan kuesioner dan memeriksa kadar gula darah dengan alat pengukur gula darah.

\section{HASIL}

Kegiatan pengabdian masyarakat telah dilakukan dalam 2 kelompok peserta pasien diabetes mellitus dimana masing-masing kelompok berjumlah 15 peserta dimana setiap kelompok mendapatkan kegiatan pre test, intervensi dan post test. Hasil kegiatan tersebut dapat dilihat dari Tabel 1 sampai Tabel 3.

Tabel 1. Karakteristik Peserta Diabeter Mellitus Yang Mengikuti Edukasi Manajemen Diri Diabetes Mellitus Di Wilayah Kerja Puskesmas Pancur Batu Kabupaten Deli Serdang Tahun 2019 (n=30)

\begin{tabular}{lcc}
\hline Karakteristik Peserta & Jumlah & Persentase(\%) \\
\hline Umur & 3 & 10,0 \\
$35-44$ & 16 & 53,3 \\
$45-59$ & 9 & 30,0 \\
$60-74$ & 2 & 6,7 \\
$75-90$ & & \\
Jenis Kelamin & 11 & 36,7 \\
$\quad$ Laki-Laki & 19 & 63,3 \\
$\quad$ Perempuan & & \\
Status Perkawinan & 26 & 86,7 \\
$\quad$ Menikah & 4 & 13,3 \\
$\quad$ Duda/Janda & & \\
Pendapatan & 7 & 23,3 \\
$\quad>2.132 .188-4.500 .000$ & 23 & 76,7 \\
$\quad$ 2.132.188 & & \\
Pekerjaan & 15 & 50,0 \\
$\quad$ Ibu Rumah Tangga & 1 & 3,3 \\
PNS/BUMN/ABRI & 5 & 16,7 \\
$\quad$ Wiraswasta & 3 & 10,0 \\
$\quad$ Pensiunan & 6 & 20,0 \\
$\quad$ Lain-lain & & \\
Lama Mengalami DM & 16 & 53,3 \\
$\quad$ < 1 Tahun & 9 & 30,0 \\
$\quad \geq 1$ - < 5 Tahun & 3 & 10,0 \\
$\quad$ 5 - <10 Tahun & 2 & 6,7 \\
$\quad$ 10 - <15 Tahun & & \\
\hline
\end{tabular}

Tabel 2. Gambaran Skor Minimum, Maximum dan Mean serta SD Efikasi Diri, KGD, dan Kualitas Hidup Pasien DM Yang Mengikuti Edukasi Manajemen Diri Diabetes Mellitus Di Wilayah Kerja Puskesmas Pancur Batu Kabupaten Deli Serdang Tahun 2019.

\begin{tabular}{lcccc}
\hline \multicolumn{1}{c}{ Skor } & Min & Max & Mean & SD \\
\hline Efikasi Diri Pre & 32 & 62 & 51,40 & 7,33 \\
Efikasi Diri Post & 49 & 68 & 57,63 & 3,75 \\
\hline
\end{tabular}

\begin{tabular}{lcccc}
\hline \multicolumn{1}{c}{ Skor } & Min & Max & Mean & SD \\
\hline KGD Pre & 86 & 546 & 224,77 & 129,52 \\
KGD Post & 89 & 486 & 221,23 & 123,04 \\
Kualitas Hidup Pre & 31 & 85 & 62,33 & 14,11 \\
Kualitas Hidup Post & 34 & 94 & 72,50 & 15,03 \\
\hline
\end{tabular}

Tabel 3. Perbedaan Skor Efikasi Diri, KGD, dan Kualitas Hidup Sebelum dan Sesudah Diberikan Intervensi Edukasi Manajemen Diri Diabetes Mellitus Di Wilayah Kerja Puskesmas Pancur Batu Kabupaten Deli Serdang Tahun 2019.

\begin{tabular}{lc}
\hline \multicolumn{1}{c}{ Pasangan } & Mean \\
\hline $\begin{array}{l}\text { Mean skor efikasi diri pre - skor } \\
\text { efikasi diri post }\end{array}$ & $-6,23$ \\
$\begin{array}{l}\text { Mean skor kadar gula darah pre - skor } \\
\text { kadar gula darah post }\end{array}$ & 3,53 \\
$\begin{array}{l}\text { Mean skor kualitas hidup pre - skor } \\
\text { kualitas hidup post }\end{array}$ & $-10,17$ \\
\hline
\end{tabular}

\section{PEMBAHASAN}

Hasil pengabdian kepada masyarakat menunjukkan bahwa berdasarkan hasil pengukuran perbedaan rerata skor efikasi diri post edukasi manajemen diri diabetes mellitus dengan rata-rata skor efikasi diri pre edukasi manajemen diri diabetes mellitus didapat selisih dua pengukuran tersebut sebesar 6,23. Hasil tersebut telah sesuai dengan kriteria penilaian yang direncanakan yaitu terjadi penurunan sebesar 10 persen dari skor pre test efikasi diri atau $(6,23$ : ( $10 \%$ x 51,40)) yaitu 12,12 persen. Dari hasil ini, menunjukkan bahwa edukasi manajemen diri diabetes mellitus dapat meningkatkan efikasi diri dalam waktu lebih kurang 2 minggu setelah edukasi manajemen diri diabetes mellitus. Hasil pengabdian kepada masyarakat ini selaras dengan penelitian (Sharifirad et al., 2013) menunjukkan adanya hubungan yang erat antara efikasi diri dengan perawatan diri sendiri melalui edukasi manajemen diri diabetes mellitus.

Berdasarkan hasil pengukuran perbedaan ratarata skor kadar gula darah post edukasi manajemen diri diabetes mellitus dengan rata-rata skor kadar gula darah pre edukasi manajemen diri diabetes mellitus didapat selisih dua pengukuran tersebut sebesar 3,53. Edukasi manajemen diri diabetes mellitus sudah dapat memberikan kontribusi terhadap penurunan kadar gula darah peserta namun penurunannya masih kecil hanya mencapai 1,57 persen dari penurunan 10 persen kadar gula darah pre yang diharapkan atau sebesar $(3,53:(10 \% \mathrm{x}$ 224,77)). Ada beberapa hal yang menyebabkan penurunan kadar gula darah ini sangat kecil, kemungkinan diantaranya adalah waktu post test yang sangat singkat yaitu \pm 2 minggu, masih ada peserta yang kurang kepatuhannya dalam menjalankan hasil edukasi, ketidaksamaan waktu 
makan peserta ketika post test dilakukan. Namun jika dilihat dari master data dari 30 peserta ada 16 peserta $(53,33 \%)$ kadar gula darah dalam rentang kendali normal $\leq 200 \mathrm{mg} / \mathrm{dl}$. Hasil pengabdian kepada masyarakat ini senada dengan penelitian (Gultom \& Siregar, 2017), menunjukkan adanya penurunan kadar gula darah setelah dilaksanakannya model pengembangan efikasi diri melalui edukasi manajemen diri diabetes mellitus namun tidak ada pengaruh yang signifikan yang ditunjukkan dengan $\mathrm{p}$ value 0,589 .

Berdasarkan hasil pengukuran perbedaan ratarata skor kualitas hidup post edukasi manajemen diri diabetes mellitus dengan rata-rata skor kualitas hidup pre edukasi manajemen diri diabetes mellitus didapat selisih dua pengukuran tersebut sebesar 10,17. Hasil tersebut telah sesuai dengan kriteria penilaian yang direncanakan yaitu terjadi penurunan sebesar 10 persen dari skor pre test kualitas hidup atau $(10,17$ : $10 \%(62,33)$ yaitu 16,34 persen. Dari hasil ini, menunjukkan bahwa edukasi manajemen diri diabetes mellitus dapat meningkatkan kualitas hidup dalam waktu lebih kurang 2 minggu setelah edukasi manajemen diri diabetes mellitus. Edukasi manajemen diri diabetes mellitus dapat memberi pengaruh yang berarti pada kualitas hidupnya. (Gultom \& Siregar, 2017; Kargar Jahromi et al., 2015).

\section{KESIMPULAN}

Dari hasil pengabdian kepada masyarakat dapat disimpulkan bahwa edukasi manajemen diri diabetes mellitus dapat meningkatkan efikasi diri, menurunkam kadar gula darah dan meningkatkan kualitas hidup.

\section{DAFTAR PUSTAKA}

Amelia, R., Ariga, R. A., Rusdiana, Sari, M. I., \& Savira, M. (2018). Self-efficacy in type 2 diabetes mellitus patients and the relationship with the quality of life in Medan city. Journal of Physics: Conference Series. 6596/1116/5/052003

Ariani, Y., Sitorus, R., \& Gayatri, D. (2012). Motivasi dan Efikasi Diri Pasien Diabetes Melitus Tipe 2 Dalam Asuhan Keperawatan. Jurnal Keperawatan Indonesia. https://doi.org/10.7454/jki.v15i1.44

Association, A. D. (2018). Diabetes Care - Standards of medical care in diabetes 2018. The Journal of Clinical and Applied Research and Education.

Badan Penelitian dan Pengembangan Kesehatan. (2013). Riset Kesehatan Dasar 2013. Riset Kesehatan Dasar 2013.

Centers for Disease Control and Prevention, U. D. of H. and H. S. (2017). National Diabetes Statistics Report, 2017. Estimates of Diabetes and Its Burden in the United States Background. Division

\section{of Diabetes}

https://doi.org/10.2196/jmir.9515

Forbes, J. M., \& Cooper, M. E. (2013). Mechanisms of diabetic complications. In Physiological Reviews. https://doi.org/10.1152/physrev.00045.2011

Gakhar,M., Hazen,A., Khanchandi,H., Stitcher,A., Maddox,N., 2008. Diabetes Self-Management Education (DSME). Establishing A Community Based DSME Program For Adults With Type 2 Diabetes To Improve Glycemic Control. An Action Guide, Atlanta : Central Diseases Control And Prevention

Gultom, A., \& Siregar, A. (2017). Self-efficacy development model for strengthening quality of life diabetes mellitus patients at Darussalam Puskesmas Medan, Indonesia. International Journal of Medical Science and Public Health. https://doi.org/10.5455/ijmsph.2017.08228111 02017

Kargar Jahromi, M., Ramezanli, S., \& Taheri, L. (2015). Effectiveness of diabetes self-management education on quality of life in diabetic elderly females. Global Journal of Health Science. https://doi.org/10.5539/gjhs.v7n1p10

Kemenkes RI. (2018). Hasil Utama Riset Kesehatan Dasar 2018 Kementrian Kesehatan Badan Penelitian dan Pengembangan Kesehatan. Balitbangkes. https://doi.org/1 Desember 2013

Sharifirad, G., Azadbakht, L., Feizi, A., Kargar, M., \& Mohebi, S. (2013). Review the key role of selfefficacy in diabetes care. Journal of Education and Health Promotion. https://doi.org/10.4103/2277-9531.115827

World Health Organization. (2016). Global Report on Diabetes. Isbn. https://doi.org/ISBN 978924 1565257 